\title{
THE POSSIBILITY OF MORAL CULTIVATION IN THE ONTOLOGICAL OBLIVION: A RE-EXPLORATION OF HONGZHOU SCHOOL OF CHAN BUDDHISM THROUGH GUO XIANG
}

\author{
Christine Abigail L. Tan \\ Nanyang Technological University, Singapore
}

\begin{abstract}
Chan Buddhism as we know it today can perhaps be traceable to what is known as the Hongzhou school, founded by Mazu Daoyi. Although it was Huineng who represented an important turn in the development of Chan with his iconoclastic approach to enlightenment as sudden rather than gradual, it was in Huineng's successor, Mazu, where we saw its complete radicalization. Specifically, Mazu introduced a radicalized approach of collapsing substance (體 $t i$ ) and function (用 yong), as well as principle (理 li) and phenomena (事 shi), into a complete overlap. As a result of this radicalization, the Hongzhou lineage received some strong criticisms, the most important of which was possibly by Guifeng Zongmi, of the Heze lineage. Zongmi criticized Mazu for his supposed antinomianism, claiming that Mazu's approach completely stunts moral and religious cultivation. Due to their commitment to "suchness" rather than deliberate theory, however, Hongzhou never bothered to answer Zongmi's critique. As such, it is the goal of this article to utilize Guo Xiang's philosophy as a tool to understand the implicit Hongzhou response to Zongmi. As I shall demonstrate, his philosophical enterprise shares the same ontology of absolute oblivion which Hongzhou was also predicated upon and is, therefore, a possible alternative to understanding what could have been the Hongzhou response to the alleged antinomianism.
\end{abstract}

\section{INTRODUCTION}

Chan Buddhism, or what is now more popularly referred to as Zen Buddhism, is commonly known as an exemplar of the height of absurdity and bizarre behavior, even to the point of being too nonsensical. However, when Chan or Zen Buddhism talk about things such as "the sound of one hand clapping," what do they really mean - is it simply without explanation and a history of purely "just that," or is there 
coherence underneath the seemingly absurd? In order to answer this, we must take a step back into certain episodes of its origins. For one, and as we shall see, before it developed into later Chan Buddhism as we know it, it had often been attacked for its non-dualistic worldview and supposed tendency towards antinomianism. (Gregory 1991) In fact, one of the strongest critiques comes from within Chan itself, when Guifeng Zongmi, of the Heze lineage, criticized Mazu Daoyi, of the Hongzhou lineage and whom we now possibly consider as the most important Chan teacher in the history of Chinese Buddhism, for his disregard for the practice of dhyana. Zongmi thought that such radical subitism, for which Chan is known today, was a dangerous stance regarding practice and morality. (Gregory 1991, 245)

Indeed, Classical Chan Buddhism, as we now know, can be traceable to what is known as the Hongzhou school. Its founder, Mazu Daoyi, is a student of Huairang, who is said to be one of the best disciples of the (disputed) sixth patriarch himself, Huineng. ${ }^{2}$ Other notable Hongzhou members include Mazu's dharma heir, Baizhang Huaihai, and Huangbo Xiyun, who was in turn Baizhang's dharma heir. Later on, Huangbo became a teacher to Linji Yixuan, founder of the Linji School or Rinzai, which is arguably the most dominant in Chan Buddhism, and the archetype of Classical Chan, which continued to blossom during the Song dynasty side-by-side Neo-Confucianism. (McRae 2003b) Linji School is known for its iconoclastic practices such as shouting and hitting as well as controversial remarks such as "kill the buddha," 3 but such practices can indeed be traceable to the theories of Mazu, supplemented by Huangbo. As such, Hongzhou is an integral domain when it comes to understanding the workings of Chan Buddhism itself, and Master Ma is an important defining figure. In fact, it was during the blossoming of the Hongzhou school which Master Ma founded in the Tang dynasty, also commonly referred to as "Middle Chan," that Chan Buddhism flourished the most - a time which scholars such as John McRae refer to as the "golden age of Chan." (McRae 2003b, 19)

As such, Zongmi's attack against Mazu can also be said to be an attack on Chan Buddhism as it is now generally understood. However, the succeeding Hongzhou Buddhists never really bothered to answer Zongmi directly, and this was perhaps because of their radical belief in "suchness," but also precisely why it is worthy of our attention now. Thus, in this paper, I aim to offer a possible solution to Zongmi's critique by drawing on Neo-Daoist philosopher Guo Xiang. As I shall demonstrate, his philosophical enterprise shares the same ontology of absolute oblivion that the Hongzhou School is also predicated upon.

In order to understand this idea of "suchness" and the radical subitism that the Hongzhou school exemplified, however, we must first discuss how exactly this strand of Chan Buddhism rose to dominance and what makes Hongzhou "iconoclastic"4 against the backdrop of the notion of "gradual enlightenment" that came before it.

\section{GRADUAL AND SUDDEN ENLIGHTENMENT: MAHAYANA ORTHODOXY FROM NORTHERN AND SOUTHERN SCHOOLS}

The initial teachings of Chan Buddhism originated from the legendary coming of Bodhidharma from the "West" 5 into China with the purpose of spreading the 
teachings of Maháyána. The accounts of how exactly this took place have been disputed time and again, but such biographical history of Bodhidharma is of no concern to us here. Rather, what is noteworthy is the iconic story of how the Second Patriarch, the successor of Bodhidharma, sought to understand the very teaching of Buddhism. The story goes as follows:

Bodhidharma sits facing the wall. His future successor (Huike) stands in the snow and presents his severed arm to Bodhidharma.

He cries: "My mind is not pacified. Master, pacify my mind."

Bodhidharma says: "If you bring me that mind, I will pacify it for you."

The successor says: "When I search my mind, I cannot hold it."

Bodhidharma says: "Then your mind is pacified already" (Ekai 1934).

This is an important story because it shows one of the most important teachings of the core of Chan Buddhism, being that enlightenment does not come from any external factor but within. Hence, no one else, not even Bodhidharma, can "pacify the mind," except one's self. In other words, Buddha-nature is always already within one's own self, but because it is "covered" by "delusion" or deluded thoughts, it cannot "appear." "The task, therefore, is to rid one's self of the external objects and thoughts that obstruct the buddha-nature.

Generally speaking, there were two major methods that arose as a way to do this. These are commonly referred to as Northern and Southern Schools. Historically speaking, the lineage of patriarchy from Bodhidharma passed to Huike, making him the Second Patriarch. Succeeding him is Sengcan, who is the Third Patriarch, who then passed it on to Daoxin, the Fourth Patriarch, and Hongren, the Fifth Patriarch. The divide begins with the disputed Sixth Patriarch: the Northern School contends that it was Shenxiu, but Shenxiu's student, Shenhui, claimed that it was actually Huineng.

Without going into much detail, it is sufficient to note that Shenhui thought of the Northern School of Shenxiu, Faure notes, "as representatives - or rather sources of a false Chan tendency, that of gradualism," (Faure 1997, 4) that is, the notion that one needs to constantly practice and meditate, gradually emptying the mind of deluded thoughts, in order to reach enlightenment. The contrast and disagreement between the two schools are perhaps more clearly shown in a passage from the Platform Sutra, where the Fifth Patriarch (Hongren) supposedly called in his disciples with the intention of selecting a dharma heir. He said:

Let me preach to you. For people in this world, birth and death are vital matters. You disciples make offerings all day long and seek only the field of blessings, but you do not seek to escape from the bitter sea of birth and death. Your own self-nature obscures the gateway to blessings; how can you be saved? All of you return to your rooms and look into yourselves. Men of wisdom will of themselves grasp the original nature of their prajna intuition. Each of you writes a verse and brings it to me. I will read your verses, and if there is one who is awakened to the cardinal meaning, I will give him the robe and the Dharma and make him the Sixth Patriarch. Hurry, hurry! (The Platform Sutra of the Sixth Patriarch 2012, §4). 
During this time, Shenxiu was the head monk, and so he thought no one else would present a mind-verse but him. At midnight, then, and with the sole intention of gaining the Dharma, Shenxiu wrote:

The body is the Bodhi tree,

The mind is like a clear mirror.

At all times, we must strive to polish it,

And must not let the dust collect (The Platform Sutra of the Sixth

Patriarch 2012, §6).

Upon seeing this the next morning, Hongren told the disciples to practice in accordance with it such that it can keep them from evil ways. The disciples then recited the verse that Shenxiu wrote and felt great admiration. Later on, however, Hongren calls on the head monk Shenxiu in private to tell him that he has not reached true understanding yet and told him to think about it more for a day or two. The Sutra, however, tells us that even after several days, Shenxiu failed to come up with a fitting verse. Meanwhile, when an acolyte who was reciting the above verse passed by the threshing room where Huineng was working, Huineng overheard the verse and immediately knew that whoever wrote the verse did not have the true understanding of the cardinal meaning. Huineng then asked the acolyte what this verse is and when the acolyte told him it was by head monk Shenxiu, he asked the acolyte to bring him to the hall where Shenxiu's verse was written. Because Huineng was illiterate, however, he asked someone else to read it for him, and soon after, he was awakened to the cardinal meaning. Wanting to offer his own original mind, he asked someone who was literate to write the following verse for him (there are two versions in the Platform Sutra):

Bodhi originally has no tree,

The mirror also has no stand.

Buddha nature is always clean and pure;

Where is there room for dust? (The Platform Sutra of the Sixth Patriarch

$2012, \S 8)$.

The other version reads:

The mind is the Bodhi tree,

The body is the mirror stand.

The mirror is originally clean and pure;

Where can it be stained by dust? (The Platform Sutra of the Sixth Patriarch $2012, \S 8)$.

It is said in the Sutra that the disciples were all amazed at his verse and that the Fifth Patriarch, Hongren, realized how Huineng had a splendid understanding of the cardinal meaning. However, afraid to let everyone know, Hongren called Huineng privately and taught him the Diamond Sutra, which Huineng immediately understood. There, Huineng was given the "Dharma of Sudden Enlightenment," and Hongren told him: 
I make you the Sixth Patriarch. The robe is the proof and is to be handed down from generation to generation. [...] 'From ancient times, the transmission of the Dharma has been as tenuous as a dangling thread. If you stay here, there are people who will harm you. You must leave at once (The Platform Sutra of the Sixth Patriarch 2012, §9).

Huineng then set out to the South, hence the reference, Southern School. Now this account, real or imagined, shows us the gist of the Southern shift. Instead of actively excluding thoughts altogether as Shenxiu does, the Southern school emphasizes that it is that the realization that there is no alighting of dust that can possibly happen in the first place wherein buddha-nature can arise, hence re-affirming the Chan claim that buddha-nature is always already within, but also going beyond that and claiming that there is no mirror. In other words, while Shenxiu and the gradualism camp contends that the mind or mirror can only manifest its brightness by slowly and gradually polishing the dust from the mirror, Huineng contends that there is no mind or mirror for the dust to alight. Thus, external thoughts cannot obstruct anything if there is no "thing" (as Shenxiu understood the mind to be) to obstruct. For Huineng and the Southern School, buddha-nature is the mind, but this mind is absolute because it is nothing, no-thing, non-object, non-conditional.

\section{HONG-ZHOU SCHOOL: RADICALIZED SUDDENNESS}

It is from this lineage of Southern School Chan that Hongzhou school emerged, and its founder, Mazu Daoyi, is traditionally depicted as the successor to the Huineng lineage, as previously discussed. It is also from this Hongzhou line that all succeeding Chan schools would derive from, by virtue of the Linji School's dominance. Needless to say, Hongzhou became the successor to the Chan orthodoxy. As Poceski $(2007,19)$ notes, "the rise of the Hongzhou school represented a consolidation and maturation of the Chan movement, a culmination of its evolution during the Tang period," with its founder, Mazu Daoyi, depicted as a figure "under whom Ch'an began to flourish in China as never before."(The Blue Cliff Record 2005, xxii) Thus, the victory of the Southern School, whose teaching of sudden enlightenment was also true for the Hongzhou, culminated in the dominance of Hongzhou as the successor to Chan orthodoxy. What distinguished the teachings of Mazu, however, was its radicalization of sudden enlightenment to the point of collapsing substance and function, 體 $t i$ and 用 yong, principle and phenomena, 理 $l i$ and 事 $s h i$, into a complete overlap. In order to explain this further, let us look at Mazu's sermon in Jingde chuan deng lu:

If you attain (a realization grounded in) the teaching, then you will always be free. When the realm of reality is established, then everything becomes the realm of reality. When suchness [真如] is established, then everything becomes suchness. When the principle is established, then all things become a principle. When phenomena are established, then all things become phenomena. When the one (principle) is raised, then the many (phenomena) follow principle and phenomenon not being different 
from each other. [理事無別] ${ }^{7}$ Everything is sublime function, and there is no other principle (Mazu Daoyi in Poceski 2015, 305).

In other words, true reality is none other than "this," and we see a three-sixty degree collapse of both theory and practice. It thus takes us a step further from simply realizing that there is nowhere from which the dust can alight in the first place (as opposed to the need to polish the mirror constantly), but the implication of such claim, being that there is no One other than its universal absence from the Many. This is why Mazu also says: "Whether constructing or sweeping away, all is a sublime function; all is oneself. There is no place to stand where one leaves the Truth. The very place one stands on is the Truth; it is all one's being."(Chien 1992, 66) Buddha-nature is thus everywhere, and its pervasiveness penetrates all, including the filth and muck of all thoughts, which means that the filthy and even delusion itself is buddha. The implication of this dispersal of the buddha or truth into all phenomena would thus mean that all beings, all minds, are themselves, already buddha.

It is from this teaching that one of the most popular sayings of Mazu emerges: that "your own mind is Buddha, that is, this mind is Buddha's Mind." (Tao-I 1971, 149) This is indeed a popular line for a reason, and it is because it perfectly characterizes what the Hongzhou School had taught, that the ordinary mind is the very buddha-nature; it is, in itself, Truth, and there is nothing else but this, for this very mind is the buddha. That is why Mazu would also say that "if you are aware of this mind, you will dress, eat, and act spontaneously in life as it transpires, and thereby cultivate your spiritual nature."(Tao-I 1971, 149) Here, then, we see spontaneity as cultivation. For as long as one is aware of the functions of the mind and the reality that these are actually buddha-nature, one can be said to have been enlightened, and through this enlightenment, one can simply do about with everyday things without the need to either reject or hold on to them. Indeed, for the Hongzhou School, it is the clinging, whether it be towards the desire for external objects or even simply the idea of negation, that leads to delusion. As such, one must simply accept that all functions are themselves buddha-nature, which will accordingly make one act spontaneously.

If there is any passage that summarizes the teachings of the Hongzhou school, however, it would be a dialogue wherein Mazu likens the very act of seeking the buddha-nature with the crying of a baby:

A monk asked why the Master maintained, "The Mind is the Buddha." The Master answered, "Because I want to stop the crying of a baby." The monk persisted, "When the crying has stopped, what is it then?" "Not Mind, not Buddha," was the answer. "How do you teach a man who does not uphold either of these?" The Master said, "I would tell him, 'Not things." The monk again questioned, "If you met a man free from attachment to all things, what would you tell him?" The Master replied, "I would let him experience the Great Tao." (Tao-I 1971, 150).

Needless to say, Hongzhou School takes the notion of no-thing or emptiness into a new height, that of absolute nothingness, total lack of absolute substance, which 
allows for a complete interfusion of buddha-nature into the myriad things, making the myriad things themselves, buddha-nature, inseparable from all function, and existing only within such function. The notion of a separate buddha-nature thus now becomes a kind of clinging - a dangerous delusion. As such, one must simply let thoughts and feelings pass through, for this very thought, this very moment, and all other present moments passing through is buddha-nature.

Again, this is a kind of cultivation that requires no deliberate effort whatsoever in order to achieve enlightenment; one needs only to free the mind of artificial clinging to an absolute. One must simply let his innate nature flow without effort in order to be enlightened, allowing the mind to act spontaneously and on its own-truly giving new meaning to no cultivation as cultivation.

This radicalized iconoclastic explanation of enlightenment, however, did not go without criticism. As Buswell $(1991,341)$ notes:

By asserting that everything is enlightenment itself and that nothing wholesome needs to be cultivated and nothing unwholesome removed, Ma-tsu's approach is open to the criticism that it too easily lends itself to antinomianism...

Indeed, it may have dangerous implications regarding dhyana and morality, as was the concern of one of its strongest critics of the time, Guifeng Zongmi.

\section{ZONGMI'S CRITIQUE}

Guifeng Zongmi was a known chronicler of Buddhist traditions, but he was also a strong defender of morality and tradition. Zongmi was himself of the Heze lineage, which means that, like the Hongzhou lineage, he was of the Southern school. Thus, he also provided a criticism not just of Hongzhou but also for the other major Chan schools in favor of Heze. Zongmi criticizes the Northern school because of its dualism between unconditioned purity and delusion, or mirror and dust, due to its lack of "sudden enlightenment," which Zongmi also acknowledges. Indeed for Zongmi, it is the very misconception of the impure as purely impure that leads to impurity, without acknowledging that they are fundamentally empty and consist of no reality on their own. Similarly, he criticizes the Oxhead school as too one-sided, which sees the mind as only pure emptiness, since they argue that there is nothing to cognize in the first place. Cultivation, therefore, consists in negating everything. According to Zongmi, however, this ignores the basis from which illusions appear, and therefore is also a misconception of buddha-nature.

Although his critiques of the other two schools ground his eventual position, it is mainly his critique of the Hongzhou school that is pertinent to us here. According to Zongmi, the Hongzhou line of teaching, in affirming everything (in contrast to Oxhead, which negates everything) would inevitably mean that even greed, anger, and delusion comprise of the whole of buddha-nature and because they are themselves buddha; there is no need for rectification (because no cultivation is cultivation). In fact, for Hongzhou, it is the very attempt to do something about the free flow of these negative thoughts that is evil 
because it would then be another artificial clinging to an absolute. Thus, the liberated person just lets these thoughts roll and freely accepts things as they come. Spontaneity in this regard, that is, that there is no substance outside function, was thus unacceptable to Zongmi. For Zongmi, Peter Gregory $(1991,237)$ notes, Northern line and Hongzhou were both extremes; whereas the Northern line regards everything altogether as false, Hongzhou regards everything altogether as true, and this "collapsing essence ( $t i)$ into function (yong)" can lead to considerable consequences with regard to the need for religious practice. According to Zongmi, the problem with Hongzhou really is that Mazu, ${ }^{8}$ in collapsing substance/essence with function, misunderstands the difference between them in that they are neither the same nor different. This is significant because while Zongmi agrees that Buddha is everywhere and that there is a need for sudden enlightenment or awareness of function as substance, this only makes sense to people who are actually already enlightened and not to a regular deluded person. Indeed, Buswell $(1991,341)$ notes that: "The approach of the Hung-chou school was further subject to charges of elitism as well since Ma-tsu explicitly states that his approach is intended only for 'a person of the highest spiritual faculties." "This problematically seems to suggest that enlightenment is destined only for some. Thus, Mazu's model seems to propose a dangerous and almost irrelevant place for religious cultivation, given that cultivation has now become simple, spontaneous activity, when the separability of substance/essence and function is what makes religious cultivation (as movement from deluded to enlightened) possible. Although they indeed overlap, according to Zongmi, the difference between substance/essence and function is also what makes religious cultivation necessary. As such, Gregory $(1991,239)$ explains Zongmi's solution to this dilemma this way:

(He) Uses the essence/function paradigm to preserve an ethically critical duality within a larger ontological unity. While this paradigm overcomes the dualism of Northern Ch'an on the one hand, it serves to avoid the radical nondualism of Hung-chou on the other.

To be more precise, here is a diagram by Gregory $(1991,240)$ of Zongmi's proposal of a "larger ontological unity," that both encompasses substance/essence and function, as well as avoid losing their duality altogether:

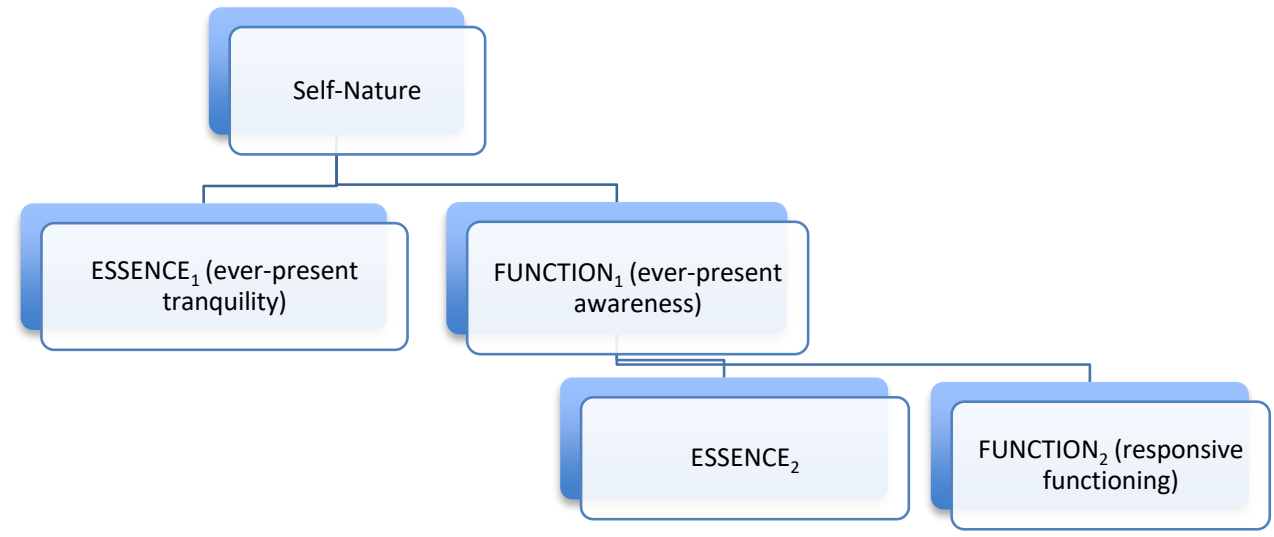


According to Zongmi, the first level is what Hongzhou loses and fails to recognize when it collapses the essence of ever-present awareness, or constant awareness of the present moment, into responsive functioning. This, too, is why Zongmi would suggest that rather than simply adopting sudden enlightenment as an end all be all, it should be followed by gradual practice in order to preserve the tranquility of self-nature. Without going further into the more elaborate details of Zongmi's solution, lest we digress, suffice it to say that Zongmi offers a considerable critique of Hongzhou. Of course, Hongzhou never answers this directly, and one would never expect them to by virtue of their very stance and commitment to practice and immediate phenomena over deliberate theory and true nature, but the question of whether it is actually valid remains a significant question to ask.

To summarize, Zongmi thinks that a complete collapse of essence and function leads, at the worst, to the antinomian treatment of religious cultivation that stunts enlightenment, and at best, to the implied elitism of the Hongzhou school. However, does the lack of Zongmi's first-level ontological unity actually lead to this dilemma? In order to answer this, I would like to revisit a $3^{\text {rd }}$-century Neo-Daoist philosopher, Guo Xiang, who also explored the compatibility of absolute contingency as an absolute necessity, or the elimination of a metaphysical being/non-being, with the goal of looking for a possible solution to both the alleged elitism as well as disregard for cultivation and moral practice that the Hongzhou is being accused of. Moreover, whereas in the context of the Hongzhou school, they never really had a reason to bother to counter the attack of Zongmi, Guo Xiang actually lived in a predominantly Confucian time and indeed even sought to amalgamate Daoist and Confucian thought, that is, nature and society or 自然 ziran and 名教 mingjiao. ${ }^{9}$

\section{A COGNITIVE ACCOUNT OF THE ONTOLOGICAL OBLIVION: GUO XIANG ON TRACES AND CULTIVATION}

Guo Xiang is the most renowned commentator of the Zhuangzi; however, his commentary can be said to be idiosyncratic in that it actually articulated his own philosophy and projected it into the Zhuangzi. In any case, it should be noted that although Guo Xiang may have influenced Chan thought, there is no evidence to support the case. Hence, my revisiting of his philosophical enterprise has less to do with tradition or intellectual history in the sense that the influencer can help enlighten the influenced, but rather, is a purely philosophical activity that explores the effects of the ontological claim, which collapses substance and function into each other. Needless to say, it would be a stretch to claim that the philosophy of Guo Xiang is identical to that of Hongzhou or Mazu's, but at the very least, we see an ontological similarity, as previously mentioned. Moreover, the same theme of the genius of the absurd that is apparent in some of the Daoist thought is shared by Chan Buddhism, and both speak of the dao in an ontological regard, so a common conceptual ground most definitely exists, which makes the use of Guo Xiang a justified conceptual bridge.

Now my task is to substitute Guo Xiang's articulation of an ontological theory for Hongzhou, and it is a simple yet complex task at the same time because although the basic premises are the same, the terminologies are entirely different. Nonetheless, 
what is most distinctive about Guo Xiang's philosophy (as with Hongzhou) is his radicalization of spontaneity. This then derives from his belief that non-being cannot give birth to being. Indeed there is no such thing as the abstract concept of nonbeing as such; we simply use the term nothing or 無 $w u$ in order denote that there simply is nothing behind the function of reality. That is, whatever the function or phenomenon, that is all the substance that there is, without any metaphysical canopy nor any underlying unified substance. Alan Chan $(2014,221)$ calls this view that is reflected in the Zhuangzi and supported by Guo Xiang as the "Daoist Oblivion," and is explained by Guo Xiang in Chuang-Tzu: A New Selected Translation with an Exposition of the Philosophy of Kuo Hsiang (2016, 58-59):

Tao is prior to things. But Tao is nothing. Since it is nothing, how can it be prior to things? We do not know what is prior to things, yet things are continuously produced. This shows that things are spontaneously what they are. [...] Though being may change in thousands of ways, it cannot change itself into nonbeing. Therefore, there is no time when there is no being; being eternally exists.

In other words, and similar to Mazu, the substance or nonbeing, or even perfect tranquility, cannot be held separate from function and phenomena precisely because such pure substance does not exist: there is no substance apart from function. Although these terminologies of substance and function did not exist yet during Guo Xiang's time, it is this very same ontology of absolute oblivion that leads to Guo Xiang's notion of spontaneity or self-so; because there is nothing that is actually purely nothing, then there is nothing that is not spontaneous or self-so. In light of Guo Xiang's ontology, we can see how it is Zongmi's very critique against the Oxhead that is proof for the validity of the Hounzhou premise. Thus spontaneity here is meant as going along with one's nature and essence at that very moment, but because this is a very radicalized spontaneity where the dao is always already scattered everywhere, ${ }^{10}$ everything is just that: moments, fleeting and changing. This can be understood more by Guo Xiang's theory of causality or lack thereof as caused by its extremity. In his commentary to the Zhuangzi, he $(2016,59)$ notes:

We may claim that we know the causes of certain things. But there is still the question: What is the cause of these causes? If we continue to ask this question again and again, we have to stop at something that is spontaneously self-produced and is what it is. We cannot ask about the cause of this something. We can only say that it is.

That is to say, that although we think it makes sense to talk about what causes what because we can say that X causes $\mathrm{Y}$ and $\mathrm{W}$ causes X. Ultimately, however, we will not be able to find any first cause; thus, there is ultimately nothing that causes $\mathrm{W}$, and thus nothing that causes $\mathrm{Y}$, and thus nothing that ultimately causes $\mathrm{X}$. In other words, because everything is caused by everything, nothing is actually caused by anything. The difficulty in understanding Guo Xiang's philosophy lies in this very paradox of radicalization, but what we see here is hardly iconoclastic in terms of Chinese 
intellectual tradition. There is a Chinese idiom,物極必必 wu ji bi fan, meaning that when things are pushed to their extremes, they reverse into the opposite - a concept that is present in the Laozi $^{11}$ and can be traced to as far back as the Yijing. ${ }^{12}$ Moreover, it is through this denial of linear causation that Guo's philosophy is able to smoothly maneuver for the complete fusion of substance and function, of the essence and the various phenomena, which lead to the inseparability and interchangeability of one to the other in its radical extremity. In Guo Xiang, therefore, we see a philosophy of pure nothingness, but because it is pushed to the limits, it no longer is a metaphysical nothingness, hence becoming a philosophy of pure being which collapses the oneness of nothingness and multiplicity of being, leading to pure oneness of activity and change in the multiplicity of things. This is why it is only in those instantaneous moments of spontaneity that essences ${ }^{13}$ or substances are fulfilled. In Guo Xiang's words: "Nonaction does not mean nothing doing. Let everything do what it does, and then its nature will be satisfied."(Guo Xiang in Chuang-Tzu: A New Selected Translation with an Exposition of the Philosophy of Kuo Hsiang 2016, 61) Guo Xiang $(2016,63)$ is also quick to warn, however, that:

The nature of everything has its limit. If one is induced by what is beyond it, one's nature will be lost. One should disregard the inducement, live according to one's self, but not to others. If so, the integrity of one's nature will be preserved.

Indeed, being caught up with what is beyond one's nature is dangerous because then one will lose the spontaneous nature. Such inducements that are outside the spontaneous flow of the cosmos and of reality, Guo Xiang calls 跡 $j i$, which Brook Ziporyn $(2012,17)$ translates as "traces." Such traces, however, are nothing but cognitive residues of spontaneous activity. Therefore, applied to Zongmi's critique, even awareness of the function, which Zongmi deems as necessary for gradual enlightenment and cultivation, becomes a "trace" in this context because it assumes a separate self capable of exercising that cognition. As Ziporyn $(2012,126)$ notes, “Guo's notion of the self-so, and non-action, is given meaning by its contrast to traces, not to actions." In other words, Guo Xiang is saying that one must not cling unto these traces because they are delusional. Like Mazu and the rest of the Buddhists, moreover, Guo Xiang believed the self is one of these traces; that is, one must forget even this very self by means of affirming everything else. Ziporyn $(2012,67)$ notes:

The self, in this case, is a trace like any other external object and is not itself the self-so spontaneity of knowing and doing. Its traces are the same dangers possessed by traces in general; it is fixed, left inadvertently by something extrinsic, invites cognition of itself as an object, and has a tendency to be taken normatively, i.e., as a fixed determinate content that one must value, preserve, and imitate. [...] Once this self is eradicated, cognition is conquered, and the "vanishing (into) things" begins.

The epistemological account offered by Ziporyn allows us to see Guo Xiang closer to the Hongzhou; it seems that by forgetting the self, that is, the sudden 
realization, there is actually no such thing as fixed self or identity which can exercise awareness towards function/phenomena as Zongmi suggests. Thus, one also comes to see one's interconnectedness and unity with all other phenomena. In Mazu, too, buddha is everywhere - this very mind is buddha; we see that in Guo Xiang, dao is everywhere, and therefore, this very moment is the dao. This is what Guo Xiang means by 冥 ming or, as Ziporyn translates, "vanishing (into) things." Guo's notion of oneness, therefore, lies in the very diversity and inter-dependence of the organic whole by allowing spontaneity to flow freely in one's own nature, in contrast to his predecessors' 14 "forced unification of things into an abstract oneness." (Ziporyn 2012, 131) Guo Xiang thus highlights the importance of individual essence and difference, and only by following the individual natures of each thing in the world, by letting them self-so according to their innate tendency, can this one-ness be fulfilled. ${ }^{15}$

Moreover, this epistemological angle also allows us to see more clearly what Guo Xiang conceives of as moral cultivation. For Guo Xiang, the previously mentioned traces, which constitute awareness, pose a threat in the moral sense because they can often be out of date and artificial. Speaking of the sage ruler Shun and King Wu, Guo Xiang $(2016,61)$ says:

These two sages were to set the world in order when there was a turmoil. One of them did it with peaceful means, while the other by military force. They differed because their time was different. Between them, there is no difference of superiority or inferiority.

Likewise, Alan Chan $(2014,222)$ notes that "for Guo Xiang, the term 'sage' means fundamentally someone who has fully realized his nature." In other words, cultivation is merely to let one's own nature self-so. Here, we are reminded of Mazu's famous pronouncement that 即心是佛 ji xin shi fu, this very mind is Buddha, or translated more literally - the immediate and sudden mind is Budda. In the same way for Guo Xiang, to cultivate oneself is none other than fulfilling one's very nature, this nature of this given moment, albeit bound to change, but letting it flow spontaneously or 自然 zi ran. In fact, one may even interpret this as not endorsing any fixed approach towards moral cultivation and agency because there is none. Again, we see this in Mazu as well. When the governor of Hongzhou asked him: "'Master, should I eat meat and drink wine or should I not?' The Master replied, 'To eat and drink is your blessing. Not to do it also a blessing." (Tao-I 1971, 152) Similar to Guo Xiang again, it does not matter what actually happens as long as it happens spontaneously and without deliberate desire, because real evil comes from being caught up in these "traces." This is why, as Chan $(2014,223)$ notes:

It is futile and foolish to try to emulate someone else, even when that someone is a sage, or to impose a single standard on the multitude. When one understands the relativity of self-interested judgments, one comes to abide by one's own nature.

Thus, if and when this is reached, feelings such as desire, hate, and greed, being all forms of attachments or clinging, would also disappear, which addresses Zongmi's 
concern. In being able to look at the ontology of oblivion that Guo Xiang and the Hongzhou School share from an epistemological angle, therefore, we find that true evil arises from cognitive clinging to an ideal that is actually simply a "self-interested judgment" from a self that is nothing but a trace of external things. In other words, we see here that contrary to Zongmi's critique, an ontology of absolute oblivion does not necessarily ignore moral cultivation and practice but rather simply reminds us how we should have the correct cognitive treatment of moral cultivation and practice and how it ought to be from the perspective of spontaneity - never forced, never artificial. Moreover, it is not so much that Mazu was being elitist when he acknowledged that his approach is only for the highest capacity, but on the contrary, that the suddenness of enlightenment does take time and trouble - that the effortlessness which emerges from this ultimate realization requires effort, precisely because there is no one true way of getting there.

From the interpretation that we have just laid out, it is not difficult to conclude that he simply means that other approaches will look different for different people in as much as Guo Xiang acknowledged that different sage kings have different methods according to the necessity of circumstances - all things being equal. What is most important to note, however, is that the complete collapse of substance and function here can never be forced under the artificial conceptual umbrella of an "ever-present tranquility." This is because if it were to be so, then it would simply regress against the point that Mazu and the Hongzhou school were trying to make. That is that there is indeed "no mind, no buddha," no substitute for a metaphysical entity. Buddha is absolutely nothing, and therefore absolutely everything.

\section{CONCLUSION}

Huangbo was once asked about which mind is referred to whenever it is sad that "Mind is Buddha," is it the ordinary mind or the enlightened mind? The inquisitor asks: "In the teaching of the Three Vehicles, it is stated that there are both. Why does Your Reverence deny it?" To this, Huangbo replied as follows:

In the teaching of the Three Vehicles, it is clearly explained that the ordinary and Enlightened minds are illusions. You don't understand. All this clinging to the idea of things existing is to mistake vacuity for the truth. How can such conceptions not be illusory? Being illusory, they hide Mind from you. If you would only rid yourselves of the concepts of ordinary and enlightened, you would find that there is no other Buddha than the Buddha in your own Mind. When Bodhidharma came from the West, he just pointed out that the substance of which all men are composed of is the Buddha. (The Zen Teaching of Huang Po: On the Transmission of Mind 1958, 116)

It is thus not what happens in everyday phenomena that is the cause of evil. The very cause of evil is the very clinging to these phenomena and not the phenomena themselves; not the phenomena, but a particular attitude to phenomena, which leads to 
the very attachment to ideas and their negation, which are both nothing but false and artificial judgments. To recognize the immanence of the mind and of its inherent enlightenment is to recognize that delusion is none other than such cognitive clinging to an external object, even if that object is itself the "mind" as a "thing." According to Jinhua Jia $(2006,70)$, this is "not an iconoclastic innovation but drew out one of the ramifications of the ambiguous tathagata-garbha theory and made explicit what was implicit in it." That is, the teaching that buddha-nature is always already within, but because there is absolutely nothing "within," all spontaneous moments and our immediate being are always already buddha-nature. Poceski $(2007,171)$ also notes that at the very core of this Hongzhou teaching is the claim that:

... since ultimate reality is, in a way, present within oneself - in fact, it constitutes one's true nature - all one needs to do is let go of false thoughts and attachments, which hinder the spontaneous manifestation and unhindered functioning of the true mind.

What is meant here by "false thoughts and attachments," however, may seemingly be a contradiction, but we now understand this better as "traces" through Guo Xiang - that is, dead ideals and thoughts, both of affirmation and negation. Although Poceski uses here the phrase "the true mind," perhaps it might be more apt to get rid of "the" altogether, acknowledging the multiplicity, dynamicity, and indeed, the suddenness of enlightenment. Since the mind is phenomena and phenomena is mind, one is inevitably subject to change and transformation through various phenomena, making true nature and actual substance inseparable from function. Indeed through Guo Xiang and the traversing from an epistemological perspective to an ontological one and back, we understand cultivation as something that is truly and radically from within, purely self-so in as much as it is the pure vanishing of oneself into things and into the various phenomena.

Indeed, the Mind is Buddha, and Buddha is everywhere. Everywhere is this very mind, and the true mind is the unhindered self-so functioning of it, for activity never stops, and there is not a single moment when the mind is not functioning, but it can be done violence against. The danger is that it not be left to naturally self-so. Thus, the violence of immorality and of delusion comes from none other the forceful imposition from outside, and these very traces, this awareness which brings about illusions of right and of wrong, has all too often become the cause for the greatest of evils, from oppressors who thought that they were defending the one absolute truth to serial killers that had fixed images in their heads of what they thought the world should become, but these are digressions which lead to different discussion altogether.

\section{NOTES}

1. This is a famous line from a Koan by Hakuin Ekaku of the Rinzai lineage, but suffice it to say that a more comprehensive explanation is beyond the scope of this work, for reasons that the meaning is highly contested upon.

2. This is, however, contested, as will be discussed in the next section. Given that 
the source is the Platform Sutra, though, the account given in this work is not likely to be historically accurate.

3. This is a famous line from Linji, which in whole, goes: "If you meet a Buddha, cut him down; if you meet a Patriarch, cut him down; if you meet an arhat, cut him down; if you meet your parents, cut them down and if you meet your relatives, cut them down. Only thus will you be liberated (and) if you are not held by externals, you will be disengaged and comfortably independent." This passage simply means that whatever idea you have of the good, that is, whatever ideal you may have, get rid of it instantly because you will become imprisoned by that relative and value-ridden judgment which is a form of delusion. This is an idea that very much exemplifies that kind of collapse of substance/function in Hongzhou, which will be discussed in this paper. See (Lu 1971, 125)125).

4. The Hongzhou school had unconventional practices or tools for pedagogy such Mazu kicking a student in the chest, and Huangbo beating up Linji, in order to bring students to enlightenment. Linji himself was known to have used shouting loudly as a teaching device as well. (See (Buswell 1991)

5. The biographical story of Bodhidharma has been traditionally compiled by T'an-lin in the Two Entrances and Two Letters which, Jeffrey Broughton says, tells us that "the Dharma Master was the third son of a great South Indian king; he "crossed distant mountains and seas' to propagate Buddhism in North China; some ridiculed him ; he acquired two younger Chinese disciples who served him for several years." Broughton also says that the route being referred to here is the Silk Road. (See (Broughton 1999, 53)53). However, for a more detailed and nuanced biography of what was accurate and what was mostly made up. (See (McRae 2003a)

6. In the Two Entrances, it is said that "it is merely because of the unreal covering of adventurous dust that the True Nature is not revealed." (See (Broughton 1999, 9). The original Chinese in "Two Entrances/Entries and Four Practices" reads: 「但為 客塵妄想所覆, 不能顯了。」Whereas Broughton simply translates this as unreal, 妄想 wang xiang literally means wishful or vainly thinking - in other words, delusion. Like “outside” dust, or dust from outside, 客塵 ke chen, thus, delusion covers, 覆 fu, the true nature. (See (達磨二入见行觀)

7. The terms 理 $l i$ and 事 shi are important central concepts in Huayen Buddhism. In fact, Jinhua Jia notes that Mazu was "also utilized the tatha'gata-garbha notion of non-origination to advocate that "the Way needs no cultivation." Inspired by the Huayan theory of nature origination from the Tatha gata, which was an interpretation of the essence/function paradigm of the two aspects of one-mind in the Awakening of Faith, Mazu proposed that the ultimate reality of enlightenment was manifested in function, and consequently affirmed that the entirety of daily life was of ultimate truth and value." (See (Jia 2006, 6=7)6-7).

8. The attack on Hongzhou is generally believed to be an attack specifically directed towards Mazu's teachings. This is also why (other than for the sake of brevity), in the previous explication of Hongzhou radical suddenness, we only discuss Mazu. (See Jia 2006, 6-7(Jia 2006)

9. On the syncretic project of Xuanxue, as well as the place of Guo Xiang as one of its greatest thinkers, Ziporyn, explains that: "the relation between spontaneity (ziran 
自然, self-so, spontaneity, “nature") and morality (mingjiao 名教, the teaching of names) was a central concern of this movement, of which Guo is considered, along with Wang Bi 王貆 (226-249), one of the two greatest representatives. Spontaneity was commonly associated with the teachings of the Laozi and Zhuangzi, while moral endeavor, the "teaching of names" concerned with the ordering of society, was associated with Confucianism, which had been the dominant official ideology throughout most of the Han dynasty. From its inception, the Mysterious Learning movement placed the unification of the two high on its agenda. Wang Bi and He Yan 何晏 (190-249), considered the intellectual founders of the movement, both wrote commentaries to both the Daodejing and Confucian works like the Zhouyi (周易 Book of Changes) and the Analects (Lunyu 論語) of Confucius." (See (Ziporyn 2014, 399)

10. The passage says: "Tao is everywhere, but everywhere it is nothing." (See Guo Xiang (Chuang-Tzu: A New Selected Translation with an Exposition of the Philosophy of Kuo Hsiang 2016) 44).

11. The Laozi or Daodejing mentions opposites and pairs many times, especially being and non-being, or non-being as giving birth to being, and continues on to repeatedly use different kinds of opposites for metaphors, such as imageries of long and short, high and low, etc. in order to show the human tendency to think in binaries whereas reality is a totality. Needless to say, the idea of extremes reversing can perhaps be most elucidated by the first two lines of verse sixteen (16), which says: 「致虛極 , 守靜篤。萬物並作，吾以觀復。」James Legge aptly translates this as: “The (state of) vacancy should be brought to the utmost degree, and that of stillness guarded with unwearying vigor. All things alike go through their processes of activity, and (then) we see them return (to their original state)." (See (Laozi 1891)

12. The general assumption in the Yijing is that opposites bring about change, but to elucidate this point more clearly, it would perhaps be most crucial to look at the hexagram 復 $F u$, which means “Return." The hexagram is composed of six yin lines on top and one yang line at the bottom. Take note that in Yijing, lines start from the bottom upward, so this hexagram means that the time of darkness or of yin is nearing an end because it has reached its extreme and will therefore be transitioning to its opposite, that is, the light or yang. This hexagram is also often associated with the winter solstice, a season generally perceived as a time when light overcomes or wins over darkness.

13. It must also be noted that essences in Guo Xiang are in the plural because, as was previously noted, there is no one single substance, no one metaphysical absolute. This means that instead of universality, we have a confluence of pure individual substances that are different from each other in as much as one moment differs from all other moments, such that they all come together in order to form one organic whole, wherein each and every member of the whole fulfills a certain role detrimental to the flourishing of the whole.

14. It is perhaps noteworthy to mention here the founder of Хиanxue or NeoDaoist School to which Guo Xiang belongs, Wang Bi. The reason for this being that Wang Bi, in contrast to Guo Xiang total lack of ontological or metaphysical logos spermatikos, Wang Bi was himself a metaphysician who advocated that "he original substance of Heaven and Earth consists of perfectly quiescent nonbeing." (See (Lynn 
2004)284). This is worth mentioning because we might speculate on how similar this is to the Northern Chan School, which advocates a gradual kind of detachment from the world, but of course, this is a topic beyond the scope of our current discussion here.

15. Guo Xiang elaborates on this and explains: "When the water runs down from a high place to a low one, the current is irresistible. When the small things group with the small, and the large things with the large, the tendency cannot be opposed. When a man is empty and without bias, everything will contribute its wisdom to him. What will he do, who is the leader of men facing these currents and tendencies? He simply trusts the wisdom of time, relies on the necessity of circumstances, and lets the world take care of itself." (See (Chuang-Tzu: A New Selected Translation with an Exposition of the Philosophy of Kuo Hsiang 2016)

\section{REFERENCES}

The Blue Cliff Record. 2005. Translated by Thomas Cleary and J.C. Cleary: Shambhala.

Broughton, Jeffrey L. 1999. The Bodhidharma anthology: The earliest records of Zen. University of California Press.

Buswell, Robert E. 1991. The "Short-Cut" approach of K'an-Hua Meditation: The evolution of a practical subitism in Chinese Ch'an Buddhism. In Sudden and gradual: Approaches to enlightenment in Chinese thought. Edited by Peter N. Gregory, Motilal Banarsidass Publishers Pvt. Limited, pp. 321-377.

Chan, Alan K.L. 2014. Embodying nothingness and the ideal of the affectless sage in Daoist philosophy. In Nothingness in Asian Philosophy. Edited by JeeLoo Liu and Douglas L. Berger, New York: Routledge, pp 243-259.

Chuang-Tzu: A new selected translation with an exposition of the philosophy of Kuo Hsiang. 2016. Translated by Youlan Feng. China Academic Library: Springer.

Ekai. 1934. Case 41. Bodhidharma pacifies the mind. Translated by Nyogen Senzaki; Paul Repps. The Gateless Gate. Los Angeles: John Murray.

Faure, Bernard. 1997. The will to orthodoxy: A critical genealogy of Northern Chan Buddhism. Translated by Phyllis Brooks. Stanford: Stanford University Press.

Gregory, Peter N. 1991. Tsung-Mi and the signification of Buddhism. Princeton University Press.

Jia, Jinhua. 2006. The Hongzhou school of Chan Buddhism in Eighth- through TenthCentury China. Albany: State University of New York Press.

Laozi. 1891. Tao te ching. Translated by James Legge: Chinese Text Project.

Lu, K'uan Yü. 1971. Ch'an and Zen teaching. Berkeley: Shambala.

Lynn, Richard John. 2004. The classic of changes: A new translation of the I Ching as interpreted by Wang Bi. New York: Columbia University Press.

McRae, John R. 2003a. Beginnings Differentiating/Connecting Bodhidharma and the East Mountain teaching. In Seeing through Zen, encounter, transformation, and genealogy in Chinese Chan Buddhism. University of California Press, 22-44.

McRae, John R. 2003b. Seeing through Zen encounter, transformation, and genealogy in Chinese Chan Buddhism. University of California Press.

The Platform Sutra of the Sixth Patriarch. 2012. Translated by Philip B. Yampolsky. New York: Columbia University Press. 
Poceski, Mario. 2007. Ordinary mind as the way: The Hongzhou school and the growth of Chan Buddhism. Oxford: Oxford University Press.

Poceski, Mario. 2015. The records of Mazu and the making of classical Chan Literature. New York: Oxford University Press.

Sun-Face Buddha: The teachings of Ma-Tsu and the Hung-Chou School of Ch'an. 1992. Translated by Cheng Chien. Berkeley: Asian Humanities Press.

Tao-I, Kiangsi. 1971. The Mind Is the Buddha (from the Transmission of the Lamp, Chüan 6). In Original Teachings of Ch'an Buddhism. Vintage Books.

The Zen teaching of Huang Po: On the transmission of mind. 1958. Translated by John Blofeld: Grove Press.

Ziporyn, Brook. 2012. The penumbra unbound: The Neo-Taoist philosophy of Guo Xiang. USA: State University of New York Press.

Ziporyn, Brook. 2014. Guo Xiang: The Self-So and the Repudiation-CumReaffirmation of Deliberate Action and Knowledge. In Dao companion to Daoist philosophy. Edited by Liu Xiaogan. Netherlands: Springer, pp. 397-423.

“達磨二入四行觀.” (The Treatise on the Two Entrances and Four Practices). Chung Tai Chan Monastery. Accessed on February 15, 2021. http://www.ctworld.org.tw/turn/sutra/005.htm. 